Number 1

\title{
KADAR GLUKOSA DARAH DAN KOLESTEROL PADA PEDAGANG DI OBYEK WISATA SANGEH KECAMATAN ABIANSEMAL KABUPATEN BADUNG
}

\author{
Ida Ayu Made Sri Arjani ${ }^{1}$, Nyoman Mastra ${ }^{2}$, I Wayan Merta ${ }^{3}$ \\ Jurusan Analis Kesehatan Poltekkes Denpasar,Jl.Sanitasi No.1 Sidakarya Denpasar Selatan \\ Email : sri_arjani62@yahoo.com
}

\begin{abstract}
Bacground The level of glucose in the blood must be kept in a sufficient concentration to provide nutrition for body organs. But on the contrary, the concentration of glucose that is too high can have a negative impact as osmotic diuresis and cellsdehydration. Therefore, blood glucose should be maintained in a constant concentration.

Objective The purpose of this study is to describe the levels of blood glucose and cholesterol in traders at Sangeh tourist attraction, Abiansema, District of Badung.

Methods This study is a descriptive study. Population of this research was all traders at Sangeh Tourist attraction or about 132 traders. 50 sample was selected by random sampling.

Results showed blood glucose levels at any of the 50 samples, 84\% normal and 16\% higher. Blood glucose levels> $140 \mathrm{mg} / \mathrm{dL}$ by age group most in the age range 55 years and over is $12 \%$, the blood glucose levels $<140 \mathrm{mg} / \mathrm{dL}$ is also the most widely exist in the age range 55 years and over 32\%, while blood glucose > $140 \mathrm{mg} / \mathrm{dL}$ by gender be obtained at most in the female sex is as much as 10\%. Test results cholesterol levels of 50 samples of $24 \%$ normal and $76 \%$ high cholesterol levels> $200 \mathrm{mg} / \mathrm{dL}$ based on age in range 55 years and over $36 \%$ whereas cholesterol levels $<200 \mathrm{mg} / \mathrm{dL}$ at most in the age range 35 -44 year amounted to (10\%). By sex cholesterol> $200 \mathrm{mg} / \mathrm{dL}$ highs also in the female sex is as much as 60\%.
\end{abstract}

Keywords : Blood glucose, cholesterol, traders

\section{Pendahuluan}

Aktivitas fisik merupakan salah satu pilar penting dari empat pilar lainnya dalam penatalaksanaan Diabetes Melitus (DM) selain edukasi, terapi gizi medis dan intervensi farmakologis. Semakin ringan aktivitas fisik seseorang semakin sedikit pula glukosa darah yang digunakan sehingga semakin tinggi glukosa darah yang akan

\footnotetext{
1.,2.3., Jurusan Analis Kesehatan Poltekkes Denpasar Korespondensi : Ida Ayu Made Sri Arjani 1, Jurusan Analis Kesehatan, Poltekes Denpasar, Jalan Sanitasi No. 1 Sidakarya, Denpasar-Bali 80224, Indonesia.

Telp. +62-361-710 527, Fax. +62-361-710 448

Email : meditoryjournal@gmail.com
} 
disimpan dalam bentuk lemak tubuh atau gliserida 1. Hal ini didukung dengan penelitian tentang kadar glukosa darah ibu rumah tangga di Banjar Tegal Antungan Kabupataen Tabanan bahwa ada hubungan yang bermakna antara kurangnya aktivitas fisik yang dilakukan dengan tingginya kadar glukosa darah ${ }^{2} . \mathrm{DM}$ sering disebut kencing manis karena pada urine terdapat gula yang berlebih. Tingkat kadar glukosa darah menentukan apakah seseorang menderita DM atau tidak ${ }^{3}$. Gejala dan tanda-tanda penyakit DM dapat digolongkan menjadi gejala akut dan gejala kronis. Gejala akut pada mulanya adalah poliuria (banyak kencing), polidipsia (banyak minum), polipagia (banyak makan). Namun bila tidak segera melakukan pengobatan akan menimbulkan gejala akut lain yaitu kurangnya nafsu makan, mudah lelah, bahkan penderita dapat jatuh koma akibat kadar glukosa darah terlalu tinggi. Gejala kronik yang terjadi sering membawa penderita berobat pertama kali. Gejala kronik yang sering timbul antara lain: kesemutan, kulit terasa panas atau seperti tertusuk-tusuk jarum, terasa tebal pada kulit, kram, lelah, mudah mengantuk, penglihatan kabur, gatal disekitar kemaluan, gigi mudah goyah,kemampuan seksual menurun

Kadar glukosa dalam darah harus dijaga dalam konsentrasi yang cukup untuk menyediakan nutrisi bagi organ - organ tubuh. Namun sebaliknya, konsentrasi glukosa yang terlalu tinggi juga dapat memberikan dampak negatif seperti diuresis osmotik dan dehidrasi sel. Oleh karena itu, glukosa dalam darah perlu dijaga dalam konsentrasi yang konstan. Pada orang normal konsentrasi glukosa darah dikontrol dalam rentang yang cukup sempit, dalam keadaan puasa tiap pagi sebelum sarapan biasanya dibawah $100 \mathrm{mg} / \mathrm{dl}$. Konsentrasi ini meningkat menjadi 120 sampai 140 mg/dl selama sekitar satu jam pertama setelah makan, namun sistem umpan balik 
untuk kontrol glukosa darah mengembalikan kadar glukosa ke rentang normal dalam dua jam setelah absorpsi karbohidrat terakhir ${ }^{5}$. Kadar glukosa sangat ditentukan oleh keseimbangan antara jumlah glukosa yang masuk ke dalam aliran darah dan jumlah yang meninggalkannya. Oleh karena itu penentu utamanya adalah asupan makanan, kecepatan pemasukan ke dalam sel otot, jaringan adiposa, dan aktivitas glukostatik hati. Lima persen glukosa yang dikonsumsi langsung diubah menjadi glikogen di dalam hati, dan 30-40\% diubah menjadi lemak,sisanya dimetabolisme di dalam otot dan jaringan lain. Pada orang normal glukosa darah turun sedang hingga menjadi sekitar $60 \mathrm{mg} / \mathrm{dl}$ selama kelaparan berkepanjangan, tetapi tidak timbul gejala hipoglikemia karena glukoneogenesis mencegah terjadinya penurunan lebih lanjut ${ }^{6}$.

Kolesterol adalah zat berwarna putih seperti lilin yang dapat ditemukan di setiap sel tubuh karena merupakan salah satu komponen lemak (selain asam lemak bebas, trigliserida, dan fosfolipid) yang diproduksi oleh hati. Kolesterol sangat dibutuhkan oleh tubuh ${ }^{7}$. Kolesterol total merupakan total keseluruhan lemak darah yang beredar dalam tubuh manusia dan dapat ditemukan dalam sel darah merah, membran sel, dan otot $^{8}$. Meningkatnya kolesterol dapat terjadi jika seseorang memiliki factor resiko lainnya seperti DM, sehingga menimbulkan suatu kondisi dimana kolesterol menumpuk di dinding pembuluh darah arteri (aterosklerosis). LDL kolesterol merupakan jenis kolesterol yang bersifat aterosklerotik. Jika kolesterol ini semakin tinggi, maka semakin besar resikonya untuk menumpuk didinding pembuluh darah. Sebaliknya HDL kolesterol merupakan jenis pengangkut kolesterol yang baik karena mampu menyapu kolesterol yang berada didinding pembuluh darah. HDL mengangkut 
kolesterol dan dibawa ke hati untuk diolah dan diubah menjadi garam empedu' .

\section{Obyek Wisata Sangeh merupakan} salah satu obyek wisata kera di Bali yang berlokasi di Desa Sangeh, Kecamatan Abiansemal, Kabupaten Badung dan berjarak sekitar $25 \mathrm{~km}$ atau memakan waktu lebih kurang 30 menit dari ibu kota Denpasar. Selain merupakan obyek wisata Bali, Sangeh juga merupakan kawasan hutan lindung yang luas areanya sekitar 14 hektar dan sebagian besar ditumbuhi dengan pohon-pohon pala (dipterrocarpustrinervis) setinggi lebih kurang 50 meter serta dihuni oleh sekitar 700 hewan kera abu-abu (macaca faciculais). Obyek wisata ini dikelola oleh pengelola khusus yang dibentuk oleh Desa Adat ( Pekraman ) Sangeh, dengan 21 tenaga pengelola. Di samping itu, mereka juga di bantu oleh staf dari Dinas kehutanan, khususnya dari Balai KSDA (Konservasi Sumber Daya Alam), serta dari Dinas Peternakan Kabupaten
Badung ${ }^{10}$. Disepanjang jalan menuju pura terdapat kios-kios pedagang kain sebanyak 70 kios dan diareal parkir terdapat kios-kios pedagang makanan dan minuman yang berjumlah 24 kios dengan jumlah pedagang sebanyak 132 orang. Dalam melakukan aktivitasnya para pedagang lebih banyak duduk sambil menunggu tamu yang lewat. Dari hasil survey dengan 15 orang pedagang diperoleh data bahwa 3 orang diantaranya memiliki kadar gula darah antara $150-300$ $\mathrm{mg} / \mathrm{dl}, 4$ orang diantaranya memiliki kadar kolesterol antara $200-300 \mathrm{mg} / \mathrm{dl}$ dan 8 orang diantaranya belum pernah melakukan pemeriksaa darah.

Aktivitas fisik yang dilakukan seseorang bervariasi dari individu satu dengan yang lain ${ }^{11}$. Pengukuran terhadap tingkat aktivitas fisik dapat dilakukan dengan acuan jenis pekerjaan, dimana dalam arti luas pekerjaan merupakan aktivitas utama yang dilakukan manusia setiap hari. Jadi bila individu mengggeluti suatu 
Ida Ayu Made Sri Arjani, dkk., Kadar Glukosa Darah Dan Kolesterol Pada Pedagang Di Obyek Wisata Sangeh Kecamatan Abiansemal Kabupaten Badung

pekerjaan dengan aktivitas fisik yang kurang dapat meningkatkan risiko Diabetes Melitus dan juga Kelesterol. Berdasarkan hal tersebut diatas maka peneliti tertarik untuk mengangkat permasalahan dengan judul Gambaran Glukosa Darah Sewaktu dan Kolesterol Pada Pedagang di Obyek Wisata Sangeh Kecamatan Abiansemal Kabupaten Badung”.

\section{Metode}

Jenis penelitian yang digunakan adalah deskriptip, yaitu penelitian yang dilakukan untuk mendeskripsikan atau menggambarkan suatu fenomena masalah kesehatan pada sekelompok penduduk atau orang yang tinggal dalam komunitas tertentu $^{12}$. Populasi pada penelitian ini adalah seluruh pedagang di obyek wisata Sangeh yang berjumlah 200 orang. Besar sampel diambil sebanyak $25 \%$ dari populasi $^{12}$, sehingga jumlah sampel adalah 50 orang, yang diambil secara radom sampling. Data primer dikumpulkan untuk mengetahui karakteristik responden, pemberian kuesioner dilakukan untuk mengetahui pengetahuan para pedagang tentang cara pencegahan penyakit diabetes mellitus dan kolesterol dan pemeriksaan darah dlakukan untuk mengetahui glukosa darah sewaktu dan kolesterol para pedagang.

\section{Hasil}

\section{Karakteristik Responden}

Dalam penelitian ini menjadi responden adalah para pedagang di obyek wisata Sangeh dengan karakteristik sebagai berikut :

\section{Umur responden}

Tabel 1

Karakteristik Responden berdasarkan kelompok Umur

\begin{tabular}{|c|c|c|c|}
\hline No. & $\begin{array}{c}\text { Kelompok } \\
\text { Umur } \\
\text { (tahun) }\end{array}$ & $\begin{array}{c}\text { Jumlah } \\
\text { (orang) }\end{array}$ & $\begin{array}{c}\text { Prosentase } \\
(\%)\end{array}$ \\
\hline 1. & $35-44$ & 11 & 22 \\
\hline 2. & $45-54$ & 16 & 32 \\
\hline 3. & 55 ke atas & 23 & 46 \\
\hline & Jumlah & 50 & 100 \\
\hline
\end{tabular}


Umur responden berkisar antara 35 sampai 64 tahun. Dari 50 orang yang responden didapat data umur $35-44$ tahun sebanyak 11 orang, umur $45-54$ tahun sebanyak 16 orang dan umur $55-64$ tahun sebanyak 23 orang.

\section{Jenis Kelamin}

Tabel 2

Karakteristik Responden berdasarkan Jenis Kelamin

\begin{tabular}{|c|c|c|c|}
\hline No. & $\begin{array}{c}\text { Jenis } \\
\text { Kelamin }\end{array}$ & $\begin{array}{c}\text { Jumlah } \\
\text { (orang) }\end{array}$ & $\begin{array}{c}\text { Prosentase } \\
(\%)\end{array}$ \\
\hline 1. & Laki-laki & 13 & 26 \\
\hline 2. & Perempuan & 37 & 74 \\
\hline & Jumlah & 50 & 100 \\
\hline
\end{tabular}

Dari 50 orang responden, diperoleh data jenis kelamin laki-laki sebanyak 13 orang dan perempuan sebanyak 37 orang.

\section{Hasil Pemeriksaan}

\section{Kadar Glukosa Darah}

Tabel 3. Distribusi Kadar Glukosa

Darah Sewaktu Pedagang di Obyek

Wisata Sangeh

\begin{tabular}{|c|c|c|}
\hline $\begin{array}{c}\text { Glukosa } \\
\text { Darah } \\
\text { Sewaktu } \\
(\mathrm{mg} / \mathrm{dL})\end{array}$ & Jumlah & $\begin{array}{c}\text { Persentase } \\
(\%)\end{array}$ \\
\hline$<140$ & 42 & 84 \\
\hline$>140$ & 8 & 16 \\
\hline Jumlah & 50 & 100 \\
\hline
\end{tabular}

Dari 50 orang responden, diperoleh hasil pemeriksaan kadar glukosa darah sewaktu sebanyak 42 orang $(84, \%)$ yang mempunyai kadar glukosa darah normal dan sebanyak 8 orang $(16 \%)$ yang mempunyai kadar glukosa darah tinggi.

\section{Kadar Kolesterol}

Tabel 4. Distribusi Kadar Kolesterol Pedagang di Obyek Wisata Sangeh

\begin{tabular}{|c|c|c|}
\hline $\begin{array}{c}\text { Kolesterol } \\
(\mathrm{mg} / \mathrm{dl})\end{array}$ & Jumlah & $\begin{array}{c}\text { Persentase } \\
(\%)\end{array}$ \\
\hline$<200$ & 12 & 24 \\
\hline$>200$ & 38 & 76 \\
\hline Jumlah & 50 & 100 \\
\hline
\end{tabular}

Dari 50 orang responden, diperoleh hasil pemeriksaan kadar kolesterol sebanyak 12 orang $(24, \%)$ yang mempunyai kadar kolesterol normal dan sebanyak 38 
Ida Ayu Made Sri Arjani, dkk., Kadar Glukosa Darah Dan Kolesterol Pada Pedagang Di Obyek Wisata Sangeh Kecamatan Abiansemal Kabupaten Badung

orang (76\%) yang mempunyai kadar

kolesterol tinggi.

Tabel 5. Kadar Glukosa Darah dan Kolesterol pada Pedagang di Obyek Wisata Sangeh Berdasarkan Kelompok Umur

\begin{tabular}{|c|c|c|c|c|c|c|c|c|c|c|c|c|}
\hline $\begin{array}{l}\text { Kel } \\
\text { om } \\
\text { pok }\end{array}$ & \multicolumn{4}{|c|}{$\begin{array}{c}\text { Kadar } \\
\text { Glukosa } \\
\text { Darah } \\
(\mathrm{mg} / \mathrm{dL})\end{array}$} & \multicolumn{4}{|c|}{$\begin{array}{c}\text { Kadar } \\
\text { Kolesterol } \\
(\mathrm{mg} / \mathrm{dL})\end{array}$} & \multirow{2}{*}{\multicolumn{2}{|c|}{$\begin{array}{c}\text { Tota } \\
1 \\
\text { Glu } \\
\text { kosa } \\
\text { Dar } \\
\text { ah }\end{array}$}} & \multirow{2}{*}{\multicolumn{2}{|c|}{$\begin{array}{l}\text { Total } \\
\text { Kole } \\
\text { sterol }\end{array}$}} \\
\hline Usi & $\begin{array}{r}<1 \\
0\end{array}$ & 14 & $\begin{array}{r}>1 \\
0\end{array}$ & & $<2$ & & $>2$ & & & & & \\
\hline (th) & $\sum$ & $\%$ & $\sum$ & $\%$ & $\sum$ & $\%$ & $\sum$ & $\%$ & $\sum$ & $\%$ & $\sum$ & $\%$ \\
\hline $\begin{array}{l}35 \\
- \\
44\end{array}$ & $\begin{array}{l}1 \\
1\end{array}$ & $\begin{array}{l}2 \\
2\end{array}$ & 1 & 2 & 5 & 0 & 7 & 4 & $\begin{array}{l}1 \\
2\end{array}$ & 2 & $\begin{array}{l}1 \\
2\end{array}$ & 4 \\
\hline $\begin{array}{c}- \\
54\end{array}$ & 1 & $\begin{array}{l}3 \\
0\end{array}$ & 1 & 2 & 3 & 6 & 1 & 2 & $\begin{array}{l}1 \\
6\end{array}$ & 3 & 1 & 3 \\
\hline $\begin{array}{l}55 \\
\text { ke } \\
\text { atas }\end{array}$ & $\begin{array}{l}1 \\
6\end{array}$ & $\begin{array}{l}3 \\
2\end{array}$ & 6 & 2 & 4 & 8 & 1 & 3 & $\begin{array}{l}2 \\
2\end{array}$ & 4 & 2 & 4 \\
\hline Jum & $\begin{array}{l}4 \\
2\end{array}$ & $\begin{array}{l}8 \\
4\end{array}$ & 8 & 6 & 2 & 2 & 3 & 7 & 5 & 1 & 5 & 0 \\
\hline
\end{tabular}

Dari Tabel 5 diketahui kadar glukosa darah > 140 berdasarkan kelompok umur yang paling banyak berada pada rentang umur 55 tahun ke atas yaitu 6 orang
$(12 \%)$, kadar glukosa darah $<140$ paling banyak juga ada pada rentang umur 55 tahun ke atas yaitu 16 orang (32\%). Untuk kadar kolesterol > $200 \mathrm{mg} / \mathrm{dL}$ berada pada rentang umur 55 tahun keatas sebanyak 18 orang (36\%) sedangkan kadar kolesterol $<200$ $\mathrm{mg} / \mathrm{dL}$ paling banyak pada rentang umur 35-44 tahun.

Tabel 6. Kadar Glukosa Darah dan Kolesterol pada Pedagang di Obyek Wisata Sangeh Berdasarkan Jenis Kelamin

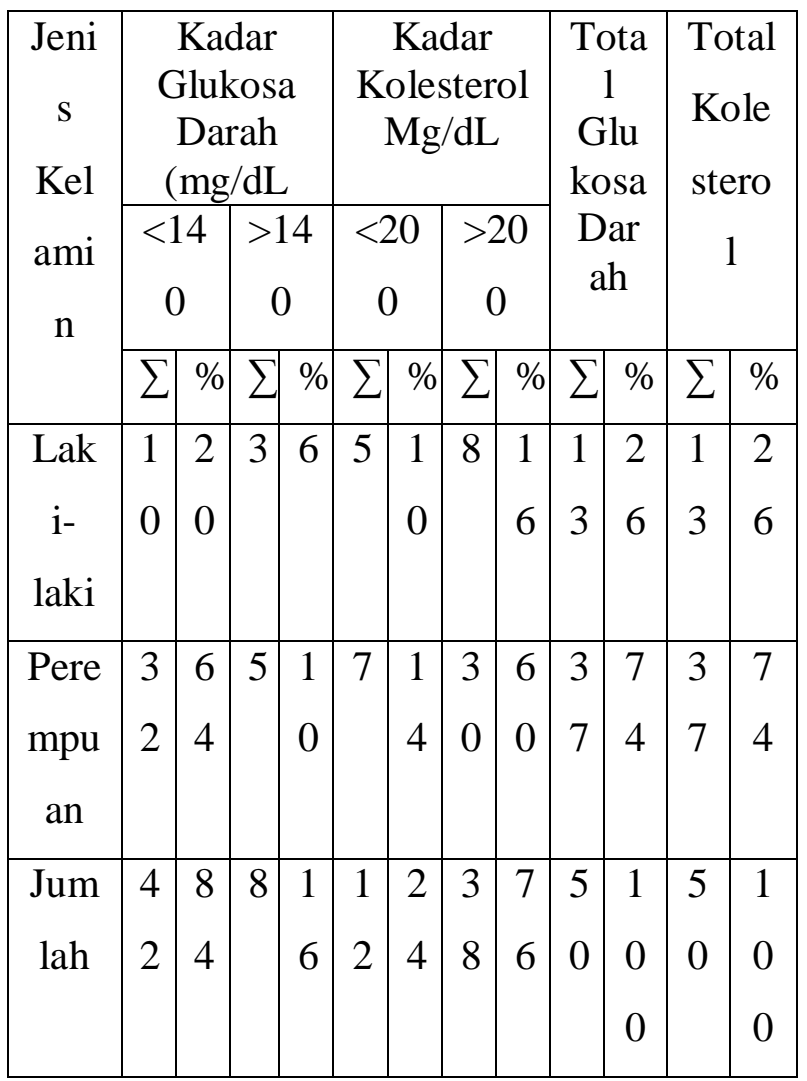


Ida Ayu Made Sri Arjani, dkk., Kadar Glukosa Darah Dan Kolesterol Pada Pedagang Di Obyek Wisata Sangeh Kecamatan Abiansemal Kabupaten Badung

Berdasarkan Tabel 6 diketahui bahwa kadar glukosa darah $>140 \mathrm{mg} / \mathrm{dL}$ berdasarkan jenis kelamin diperoleh paling banyak pada jenis kelamin perempuan yaitu sebanyak 5 orang (10\%) dan kadar kolesterol > $200 \mathrm{mg} / \mathrm{dL}$ tertinggi juga pada jenis kelamin perempuan yaitu sebanyak 30 orang $(60 \%)$.

\section{Pembahasan}

\section{Kadar Glukosa Darah}

Kadar glukosa dalam darah harus dijaga dalam konsentrasi yang cukup untuk menyediakan nutrisi bagi organ - organ tubuh. Namun sebaliknya, konsentrasi glukosa yang terlalu tinggi juga dapat memberikan dampak negatif seperti diuresis osmotik dan dehidrasi sel. Oleh karena itu, glukosa dalam darah perlu dijaga dalam konsentrasi yang konstan. Pada orang normal konsentrasi glukosa darah dikontrol dalam rentang yang cukup sempit, dalam keadaan puasa tiap pagi sebelum sarapan biasanya dibawah $100 \mathrm{mg} / \mathrm{dl}$. Konsentrasi ini meningkat menjadi 120 sampai 140 $\mathrm{mg} / \mathrm{dl}$ selama sekitar satu jam pertama setelah makan, namun sistem umpan balik untuk kontrol glukosa darah mengembalikan kadar glukosa ke rentang normal dalam dua jam setelah absorpsi karbohidrat terakhir ${ }^{5}$.

Pada penelitian ini diperoleh data bahwa dari 50 responden, sebanyak $84 \%$ responden yang memiliki kadar glukosa darah yang normal dan $16 \%$ yang memiliki kadar glukosa darah sewaktu yang tinggi. Dari 8 orang yang memiliki kadar glukosa darah > $140 \mathrm{mg} / \mathrm{dl}$ yaitu kisaran antara 149 $\mathrm{mg} / \mathrm{dl}-360 \mathrm{mg} / \mathrm{dl}$. Berdasarkan tabel 5 diketahui kadar glukosa darah > 140 berdasarkan kelompok umur yang paling banyak berada pada rentang umur 55 tahun ke atas yaitu 6 orang (12\%), sedangkan kadar glukosa darah $<140$ paling banyak juga ada pada rentang umur 55 tahun ke atas yaitu 16 orang (32\%). Pada tabel 6 diketahui bahwa kadar glukosa darah >140 
berdasarkan jenis kelamin diperoleh paling banyak pada jenis kelamin perempuan yaitu sebanyak 5 orang $(10 \%)$. Gula darah naik disebabkan oleh beberapa hal antara lain : kurangnya aktivitas fisik/kurang berolahraga, meningkatnya stress, faktor emosi, bertambahnya berat badan, usia, dan bertambahnya makanan yang di konsumsi ${ }^{13}$. Penelitian ini di dukung dengan penelitian tentang kadar glukosa darah ibu rumah tangga di Banjar Tegal Antungan Kabupataen Tabanan bahwa ada hubungan yang bermakna antara kurangnya aktivitas fisik yang dilakukan dengan tingginya kadar glukosa darah ${ }^{2}$. Dari hasil wawancara terhadap 3 orang yang memiliki kadar glukosa darah yang tinggi lebih dari 300mg/dl, diketahui bahwa mereka memang menderita kencing manis berkisar 1 tahun sampai 1,5 tahun. DR. Dr. Sidhartawan Soegondo, Sp.PD KEMD. menyatakan, sesuai dengan konsensus pengelolaan Diabetes Mellitus di Indonesia, Diabetes
Mellitus ditetapkan pada pemeriksaan kadar glukosa darah sewaktu mencapai $200 \mathrm{mg} / \mathrm{dl}$ atau lebih, dan pada pemeriksaan kadar glukosa darah puasa mencapai $126 \mathrm{mg} / \mathrm{dl}$ atau lebih ${ }^{14}$.

\section{Kolesterol}

Kolesterol selain diproduksi dengan sendirinya oleh tubuh (terutama di hati), diperoleh juga dari makanan yang dikonsumsi setiap harinya. Ada dua jenis makanan berlemak yang mengandung kolesterol yaitu lemak jenuh dan lemak tidak jenuh. Semakin banyak mengonsumsi makanan yang mengandung lemak jenuh, maka kadar kolesterol akan semakin meningkat ${ }^{9}$. Sekitar separuh kolesterol tubuh berasal dari proses sintesis (700 $\mathrm{mg} /$ hari) dan sisanya diperoleh dari makanan. Hampir semua jaringan yang megandung sel berinti mampu membentuk kolesterol yang berlangsung di retikulum endoplasma dan sitosol ${ }^{15}$. 
Ida Ayu Made Sri Arjani, dkk., Kadar Glukosa Darah Dan Kolesterol Pada Pedagang Di Obyek Wisata Sangeh Kecamatan Abiansemal Kabupaten Badung

Pada penelitian ini diperoleh data dari 50 oang responden yang hadir, diketahui bahwa sebanyak 12 orang (24\%) renponden yang memliki kadar kolesterol yang normal dan 38 orang (76\%) yang memiliki kadar kolesterol yang tinggi. Untuk kadar kolesterol > $200 \mathrm{mg} / \mathrm{dL}$ berdasarkan umur berada pada rentang umur 55 tahun keatas sebanyak 18 orang (36\%) sedangkan kadar kolesterol $<200 \mathrm{mg} / \mathrm{dL}$ paling banyak pada rentang umur 35-44 tahun sebanyak 5 orang (10\%). Berdasarkan jenis kelamin kadar kolesterol > 200 tertinggi juga pada jenis kelamin perempuan yaitu sebanyak 30 orang $(60 \%)$. Salah satu faktor yang mempengaruhi kadar kolesterol disamping pola konsumsi makanan adalah aktivitas fisik. Dilihat dari kebiasaan para pedagang di obyek wisata Sangeh kebanyakan dari mereka yang kurang bergerak, mereka kebanyakan duduk-duduk sambil menunggu tamu yang lewat..Kurang bergerak dapat meningkatkan kolesterol jahat (LDL) dan menurunkan kolesterol baik $(\mathrm{HDL})^{16}$. Kadar kolesterol yang abnormal dalam sirkulasi darah dapat menyebabkan masalah dalam jangka panjang ${ }^{17}$. Resiko terjadinya atherosclerosis dan penyakit arteri koroner atau penyakit arteri karotis meningkat pada seseorang yang memiliki kadar kolesterol total yang tinggi. Penyebab tingginya kolesterol ada faktor yaitu faktor yang tidak dapat di kontrol antara lain : keturunan dan usia. Sedangkan faktor yang dapat dikontrol antara lain : makanan yang mengandung banyak lemak, kelebihan berat badan, kurang berolahraga, merokok. Gaya hidup yan tidak sehat, stress dan minum kopi yang berlebihan.

Kesimpulan : Responden yang memiliki kadar glukosa darah normal sebanyak $84 \%$ dan yang memiliki kadar glukosa darah tinggi $16 \%$, sedangkan responden yang memiliki kadar kolesterol yang normal 24\% dan yang memiliki kadar kolesterol tinggi 76\%. Saran : Bagi pedagang di obyek 
wisata sangeh agar melakukan pemeriksaan glukosa darah dan kolesterol secara rutin untuk mengetahui secara dini kesehatan tubuhnya. Mengikuti pola makan dan pola hidup yang sehat, berolah raga secara teratur, atau mengikuti senam yoga yang sudah difasilitasi oleh bendesa adat desa Sangeh dua kali seminggu.

\section{DAFTAR PUSTAKA}

1. Asdie,A. Penemuan Baru Memerangi Diabetes Melalui Diet Golongan Darah. Yogyakarta : Bfirst, 2006.

2. Arnitasari, Kadar glukosa darah ibu rumah tangga di Banjar Tegal Antungan Kabupataen Tabanann Ditinjau dari Aktivitas Fisik. KTI, Jurusan Analis Kesehatan, Poltekkes Denpasar, 2014.

3. Hasdianah, H.R., S.I. Suprapto, Patologi dan Fisiologi Penyakit. Yogyakarta: Nuha Medika, 2014.

4. Ramaiah,S. Your Health Guide Diabetes : Jakarta : PT.Bhuana Ilmu Populer, 2003

5. Suastika,K.Tanya Jawab Seputar Obesitas dan Diabetes Memuat
Berbagai Pertanyaan nya. Awam dan Jawabannya. Denpasar : Udayana University Press, 2011.

6. Ganong, W.F. Buku Ajar Fisiologi Kedokteran . Alih bahasa oleh Braham U.P. Edisi 22. Cetakan I. Jakarta: EGC, 2008.

7. Emirfan, Healthy Habits You Must Know. Cetakan I. Yogyakarta: Javalitera, 2011.

8. Kee, J.L. Pedoman Pemeriksaan Laboratorium \& Diagnostic. Edisi 6. Jakarta: Penerbit Buku Kedokteran EGC, 2008

9. Cahyono, J.B.S.B. Gaya Hidup dan Penyakit Modern. Cetakan I. Yogyakarta: Kanisius, 2008.

10. Profil Desa Sangeh, 2014

11. Hariyanto, F. Hubungan Aktivitas Fisik Dengan Kadar Gula Darah Puasa Pada Pasien DM Tipe 2 di Rumah Sakit Umum Daerah Kota Cilegon 2013. Tersedia dalam:http://repository,uinjkt.ac.id/d space/bitstream/123456789/26376/1/ Fuad\%20Hariyanto-fkik.pdf.Diakses tanggal 25 Januari 2016, 2013

12. Notoatmodjo, S. Metode Penelitian Kesehatan. Cetakan II. Jakarta: Rineka Cipta, 2012 
Ida Ayu Made Sri Arjani, dkk., Kadar Glukosa Darah Dan Kolesterol Pada Pedagang Di Obyek Wisata Sangeh Kecamatan Abiansemal Kabupaten Badung

13. Mangoenprasodjo,.Hidup Sehat dan Normal dengan Diabetes.

Yogyakarta : Think Fresh, 2005

14. Soelistijo, S. A. Konsesus

Pengelolaan dan pencegahan

Diabetes Melitus Tipe 2 di

Indonesia. Indonesia: PB. PERKENI, 2015.

15. Murray, R.K., D.K. Granner, dan V.W. Rodwell. Biokimia Harper. Alih bahasa oleh Braham U.P. Edisi 27. Jakarta: EGC, 2009

16. Hasdianah, H.R., S.I. Suprapto. 2014. Patologi dan Fisiologi Penyakit. Yogyakarta: Nuha Medika

17. Halosehat, Penyakit yang disebabkan Kolesterol Tinggi. Terdapat dalam http://halosehat.com/penyakit/kolesterol -tinggi/penyakit-yang-disebabkankolesterol-tinggi. Diakses 25 januari 2016, 2016. 